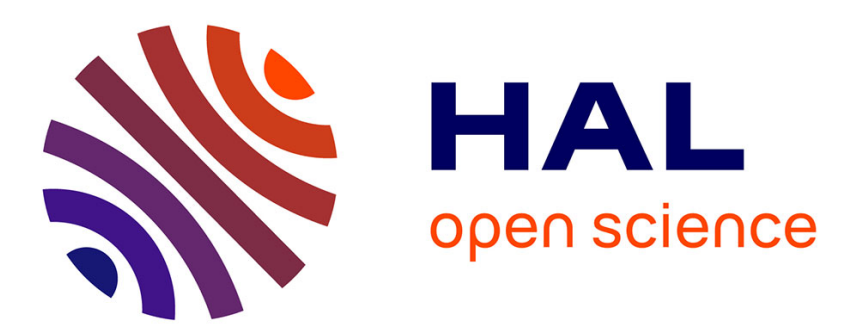

\title{
Searching the Identity of Information Systems: A Study from Interdisciplinary Contexts
}

Paolo Rocchi, Andrea Resca

\section{To cite this version:}

Paolo Rocchi, Andrea Resca. Searching the Identity of Information Systems: A Study from Interdisciplinary Contexts. International Working Conference on Transfer and Diffusion of IT (TDIT), Jun 2018, Portsmouth, United Kingdom. pp.295-305, 10.1007/978-3-030-04315-5_20 . hal-02068932

\section{HAL Id: hal-02068932 \\ https://hal.inria.fr/hal-02068932}

Submitted on 15 Mar 2019

HAL is a multi-disciplinary open access archive for the deposit and dissemination of scientific research documents, whether they are published or not. The documents may come from teaching and research institutions in France or abroad, or from public or private research centers.
L'archive ouverte pluridisciplinaire HAL, est destinée au dépôt et à la diffusion de documents scientifiques de niveau recherche, publiés ou non, émanant des établissements d'enseignement et de recherche français ou étrangers, des laboratoires publics ou privés.

\section{(c)(1)}

Distributed under a Creative Commons Attribution| 4.0 International License 


\title{
Searching the Identity of Information Systems: A Study from Interdisciplinary Contexts
}

\author{
Paolo Rocchi ${ }^{1,2}$ and Andrea Resca ${ }^{2}$ \\ ${ }^{1}$ IBM, via Shangai 53, Roma, Italy \\ ${ }^{2}$ LUISS Guido Carli Univ., via Romania 32, Roma, Italy \\ procchi@luiss.it
}

\begin{abstract}
Purpose: The present paper addresses the problem of the information systems (IS) identity, in particular it makes an attempt to identify the intellectual causes that hinder the research about the core of IS and suggests how to remove them.

Design/methodology/approach: Authors who argue on the cultural core of IS sometimes relate this argument to the 'reference disciplines' of IS such as economics and sociology. Authors rarely examine what happens in parallel domains of knowledge usually labeled as 'cognate disciplines' of IS. We fixed to extend inquiries on the close domains, in particular we have analyzed the literature of artificial intelligence, information retrieval, medical informatics, digital humanities and software engineering.

Findings: Bibliographical evidence shows how these disciplines struggle with the 'identity crisis' as IS do; more precisely thinkers share non-trivial difficulties when they argue about broad topics connected to the information technology such as the possibilities and limits of computer systems, the transfer and diffusion of technology etc.

Research implications: We recall how normally philosophy and science progress side to side and cooperate. Instead, the modern literature shows how computer science illustrates all the technical details but does not provide effective explanations to philosophers of post-computation disciplines. Several narrow theories underpin computer systems that prove to be futile to thinkers who address broad arguments. An apparent cause-effect relationship emerges between the fragmentary notions of computer science and the current 'identity crisis' of IS and cognate disciplines.

Originality/value: This study leads to a ground-breaking conclusion. In the first stage, the solution to the identity problem should not be searched inside IS but outside. As soon as possible noteworthy efforts should be made in order to improve the theoretical basis of informatics. More precisely computing theorists should develop a unified cultural frame or, at least, should make significant progress toward this direction.
\end{abstract}

Keywords: IS identity; Foundational issues; Interdisciplinary research; Computing theories. 


\section{Introduction}

The identity issue of the information systems (IS) discipline involves various arguments such as the intellectual core of IS, its relationship with other domains of knowledge, its social meaning, the possibilities and limits of the information technology (IT) etc. Theoretical research started in the 1960s and Sage pinpointed how attention should primarily be drawn to issues about engineering and computation [1]. Börje Langefors provided a model of IS as a combination of software, hardware, data, and procedures while people lie in the background [2]. Some pioneers even made attempts to conceptualize IS, like Reisig who developed an abstract meta-model derived from information theory [3]. The IS discipline evolved and still continues to evolve under the impulse of the technology, and the impact of computer technology on IS comes in and out of focus for researchers over the years. Kenneth and Jane Laudon [4] offer an overview by defining five classes of IS, which emerged one after the other over time, as a result of advances in electronics.

Starting from the eighties of the past century, authors progressively highlighted the multiple features that characterize the nature of information systems. For instance, the Frisco Report - compiled by a working group of the international federation for information processing (IFIP) - built on a semiological description of IS [5]. Cybernetics theorists extended the notion of IS to the biological domain. Experts of management information systems (MIS) looked into the organizational sides of IS, such as Lucey (2005), who provided an extensive illustration to clarify the close interrelations between business and information systems [6].

Writers became aware that the IS domain encompasses a variety of elements that go beyond the purely technical stance. Thinkers have acquired a more complex perspective that includes economical, organizational and social themes. Some of the views may not easily be reconciled and writers endeavored to integrate these various intellectual stances. Wood-Harper and others suggested the 'multiview' of information systems and may be cited as one of the first efforts to set up a multifold interpretation of IS [7]. This prismatic concern raised epistemological discussion; in fact, experts of information systems often borrow theories, methods, and good practices pertaining to various sectors. The identification and relationships with the 'reference disciplines' - e.g. economics and sociology [8] - attract the attention of Baskerville and Myer [9], who ask: Is the domain of IS simply a net importer of knowledge from other disciplines? Does IS not have any research tradition of its own?

Baskerville and Myer analyze the complex texture of topics dealing with IS, the multi-fold stances, the qualified amount of works etc. For instance, they quote the special issue of the MIS Quarterly that aims to make the reader aware of the intensive inquiries conducted in the present territory [10]. Baskerville and Myer conclude that it is time to pass from the discussion of the reference disciplines to the presentation of IS as a reference discipline [9].

Unfortunately, the progress of IT, the wealth of arguments, the flexibility to adapt to the changing environment, and the complexity of human interferences do not make the life of those who mean to follow the recommendations of Baskerville and Myer easier. Experts see the streams of research about the IS core to be somewhat intricate 
and seek a survey of the arguments under discussion. Lee observes how IS are intellectually linked to some key concepts, including 'information,' 'theory,' 'system,' 'organization,' and 'relevance' [11]. Banker and Kauffman offer a resume of the IS research in the past 50 years [12], and identify the ensuing streams of study:

1. Decision support and design science explore the application of computers in control and managerial decision making;

2. Value of information reflects on the importance of information as a commodity in the management of firms;

3. Human-Computer interaction focuses on the cognitive basis for effective systems design;

4. IS organization and strategy examine the value of IS investments at a strategic level.;

5. Economics of IS and IT investigates the impact of computer applications from managerial perspectives.

Sidorova and colleagues look into the intellectual core of IS and identify five areas in the light of the bibliographical studies published by top IS journals from 1985 through 2006 [13]. The inventoried streams of research, which turn out to be selfexplanatory, are information technology and organizations; IS development; IT and individuals; IT and markets; and IT and groups.

In summary, several authors agree on the prismatic nature of IS and on the importance of IT, but the questions remain open [14]. The considerations present distinct traits and there is no uniform consensus about the cultural identity of IS. The variety of positions reflects different intellectual influences and waves as the work of Whitley and colleagues underlines [15].

\section{What Does Happen in the Close Domains?}

\section{Interdisciplinary Viewpoint}

Traditionally, authors recognize research in information systems is interdisciplinary in nature [16]. Scholars while confronting IS' identity issue take account of the influence of the reference disciplines such as economics, sociology and management science - e.g. [8] and [9] - but we note how thinkers rarely analyse what happens in the close domains of IS, for example artificial intelligence and digital biology. These fields are usually labeled as cognate disciplines of IS since all of them have been inaugurated in consequence of the expansion of computer systems in the world; it may be said that they have a common ancestor.

Alvesson and Sandberg [17] underline the advantages of the research strategy which crosses various fields and generates more imaginative and influential results. Gibbons [18], Alderman [19] and others explain how the association of scholars belonging to different sectors is desirable since, for instance, it prevents double efforts, it makes validation easier, and enables cross-checks. The discussion held in a large community has an edge over one only held among a small circle. We personally agree that a joint intellectual effort is appropriate for the identity issue which covers a broad area of study and requires deep insights and considerations. The interdiscipli- 
nary perspective looks like an 'overhead point of view' from which one can watch the large domain influenced by the digital technologies. As an airplane pilot observes the most relevant elements in the territory from aloft and overlooks the details, so a research extended to the cognate disciplines of IS should allow scholars to grasp the most significant questions and eventually to discover their root-causes. The interdisciplinary approach is consistent with the purposes of the present work.

\section{Some Areas of Study}

We decided to look into the following cognate fields: digital humanities (DH), information retrieval (IR), medical informatics (MI), software engineering (SE), and artificial intelligence (AI).

Digital humanities is an area of study concerned with the wide-ranging application of computational technologies to the humanities [20]. Robinson and others explore the boundaries of DH [21]. Hockey argues on the limit of machines in handling data [22], while the relations between science and humanities influence the identity problems of digital humanities according to McCarty [23]. Bod believes that the cultural roots of DH - that is to say, the humanist erudition - should enlighten most foundational questions and should provide solid answers [24].

The term 'information retrieval' usually denotes the process of recovering specific information from stored data, Presently, this activity is connected to various techniques such as big data and search engines. The early years saw a heavy debate over the disparate technologies for retrieval as well as over some basic topics. Theorists tackle the questions of why, and in what sense the notion of information can be critical in IR. They even try to discern whether IR can be seen either as a field of study or as one among several research traditions concerned with information storage and retrieval [25]. Lancaster claims that the basic problems of IR are of intellectual nature and cannot be easily solved by technology alone [26]. Ellis [27] and Ingwersen [28] develop two conceptual schemes to clarify the structure of the IR field.

The earliest IT projects in medicine emerged in the 1950s. Many names have been given to medical informatics, for example health informatics, healthcare informatics, nursing informatics, and biomedical informatics; and in a sense, the list mirrors the dynamic life of this ever-expanding professional field. Lazakidou and Siassiakos [29] pinpoint how the development of electronic appliances makes it possible to cure illnesses that have never treated before. Digital systems furnish material to Kalet [30] and to Greenes and Shortliffe [31], who aim to establish medical informatics as a discipline.

The origins of the term 'software engineering' seem to date back to 1968 when a group of scholars meant to define a new distinct engineering sector, but Smith and Ali [32], Kruchten [33] and many others raise doubts whether it is really a form of engineering. Denning and Freeman [34] notice that the unanswered questions about software computation are not confined to the intellectual concerns but are also directly relevant to practitioners. In fact, statistical surveys conducted worldwide show how, yearly, more than half of the IT projects in diverse application areas are late, overbudget, unreliable, and unsatisfactory for customers (read the Standish Group Chaos 
Report http://blog.standishgroup.com/). Beizer [35] and Herbsleb [36] relate these failures to vexed issues on the essence of software programming.

The term 'artificial intelligence' covers a lot of disparate problem areas, including natural language processing, automatic programming, robotics, machine vision, automatic theorem proving, and knowledge engineering. The areas of AI are mainly united by the fact that they involve complex input and output information that is extremely difficult to compute. The number and the size of these areas, which are continuously expanding, challenges authors like Kirsh (1992) who aims to describe the common and fundamental ideas of the AI sector [37]. The very name 'artificial intelligence' implies that an explicit relationship connects or should connect an AI application to the human brain. The history written by McCorduck [38] demonstrates how, since the times of Turing, AI has captured the imagination of many scientists who are still addressing issues such as defining what intelligence is, and discovering how AI can bridge the gulf between technology and the human mind.

In summary, the current literature proves that the debates on foundational arguments are not exclusive to IS. All the mentioned post-computation disciplines struggle with the 'identity crisis' in the same manner as IS. This concern has become increasingly prevalent in recent years since none succeeds in defining a conclusive frame so far.

\section{Significant Arguments}

The approach, which involves various domains of knowledge, offers an 'overhead point of view' from which one grasps the most ponderous elements of discussion and can overlook the details: What does the interdisciplinary bibliography indicate as the most significant arguments?

The nature and roles of computing - just mentioned in Introduction - emerge amongst the knottiest foundational themes of inquiry. Let us briefly analyse three shared arguments:

i) Impact of computers on people. Human factors represent one of the most often vexed themes underpinning information systems and cognate disciplines (read the series [39]). For example, effective technology transfer often requires adaptation of work practices, reskilling, and organizational change far beyond what was initially apparent. Even a trivial fault in this area can frustrate the introduction of new software into an organization or a social group [40]. Lindgaard looks into the risk factors and the barriers to success in IT transfer, he also analyse the strategies for addressing them because of the assortment of users, customers, stakeholders, managers and technologists [41]. The literature on IS ascribes great value to the identification and dissemination of information on best practices for people [42]. Hsu and colleagues aim at evaluating the impact of digital technology in MI [43]. Specifically, they aim to understand the perception of computer use and patients' satisfaction. Russel and Norvig discuss current research of AI related to reasoning under uncertainty and knowledge representation [44]. They make comments on how specific software techniques are used in the real environment, how successful they are, and why they fail with people. In a recent book, Berry and Fagerjord [45] hold that computers challenge the way in 
which we think about culture, society and what it is typically human: areas traditionally explored by humanities.

ii) Possibility and limits of automated systems. On one side, machines prove to be more efficient than people in processing data; on the other side systems are programmed, notably they depend on humans in a substantial manner: Will the machine substitute the human mind?

Rivers of ink are still flowing about this argument, which is central to AI [46]. Amongst the skeptical we cite Peek and Newby who observe how linguistic aspects of basic importance to DH are still unanswerable [47]. For example, current computing is unable to recognize metaphor, word play, and irony. In the face of automated systems for decision assist, IS researchers seek to understand what can limit the freedom of decision-making, what can orient, influence and hamper the choice made by one or more persons [48] while Orliski and Iacono warn how the nature of the IT artifact is still unclear [49]

iii) Present and future trends in technology. Researchers discuss a very broad assortment of technical topics such as Rech and Althoff [51] who explore the next trends of artificial intelligence and software engineering that have many commonalities. Larsen and others forecast incoming challenges in DH and emphasize the role that the humanist culture will play [50]. Charikar and colleagues [52] address the document clustering optimization problem in order to enhance the performance of IR while 'big data' is a new challenge topic of inquiry for IR [53]. Mahler expects the increasing diffusion of open standards to meet the challenges facing global society [54].

\section{$3 \quad$ Philosophy and Science Progress Side to Side}

The literature demonstrates how the authors dealing with topics i), ii) and iii) struggle with broad and substantial arguments. Several issues are open since decades and the authors give the impression of being at a deadlock, so we mean to draw the reader's attention to the cooperation that should take place between science and philosophy.

Scientists and thinkers usually progress side to side as they learn from each other. The former often acquire methodological guide and impulses to establish universal principles from philosophy. On the other hand, philosophy draws from scientific discoveries fresh strength and material for conceptual generalizations. It is not rare that philosophers of science unravel intricate arguments with the aid of empirical data and the theoretical models set up by mathematicians. Unfortunately, this is not the case under discussion. Philosophers of post-computation disciplines wait to be effectively assisted by computer theorists who should explain or contribute to explain topics i), ii) and iii), instead this collaboration turns out to be rather problematic: Why?

\section{Fragmentary Explanations}

Computer science makes plain all the technical details of systems but has narrow constructions. The partial constructs of theoretical computer science (TCS) back practitioners, such as software programmers and systemists, but are far less useful to phi- 
losophers who argue on themes of general interest. Knuth was one of the first to complain about the cultural state of computer science [55]. Eden [56], Baldwin [57] and Hayes [58] look into various aspects related to the uncertain foundations of computing. They pinpoint how CS does not yet have a clear comprehensive frame, notwithstanding the large number of mathematical models in use. Tedre [59] shows how there is a great variety of different approaches, definitions, and outlooks in computer science. Denning seeks the determination of appropriate principles which should explain the essence of computing [60]. Hassan observes that what differentiates a discipline from a multidisciplinary field of interest is the development of a unique and consistent discourse [61]. More recently Rocchi [62] holds that the theories underpinning computer science exhibit the following features:

- They are narrow, in the sense that each one explores a particular topic;

- They are self-referential, in that they are scarcely connected, either logically or causally, or by shared characteristics. For example, the theory of computation and relational algebra are both involved in programming but are unrelated in point of logic.

- They are often abstract, such that constructions have faint relations with physical reality and the experimental control of the results turns out to be somewhat unachievable.

- Sometimes, they are contradictory, for example, Shannon's theory rejects semantics, whereas semioticians inquire into the making of meanings and their interpretation in communication;

- They are uncertain, since many theories have been put forward for a single topic but those theories have not yet undergone accurate scrutiny. For example, there are over thirty theories of information which present irreconcilable characters and the concept of information is still puzzling.

In summary, TCS provides assistance to specialists but turns out to be rather ineffective from the intellectual stance. There are several scientific explanations, but they often mismatch one another, and the consistent, exhaustive illustration of computing is missing. We wonder: How can philosophers clarify the intellectual profile of the disciplines that computers have generated whether the very studies of computers turn out to be rather confusing?

The contradiction is self-evident. The relationship between the fragmentary concepts of computing and the open problems of post-computation disciplines seems undeniable in the present context, thus the solution to the identity problem should not be searched inside IS but outside, more precisely in theoretical computing. TCS presents apparent limits from the philosophical stance and as a logical consequence, computing theorists should develop a unified frame or, at least, should make significant progress toward this direction. Noteworthy efforts should be made in order to improve the theoretical basis of informatics.

Speaking in general, discovering the root-cause of an issue makes experts aware of the true reasons that create an obstacle and enables those experts to remove it. Hence the advance of TCS promises to cancel the current difficulties met by authors about the cultural core of IS, MI, DI and other domains. 


\section{Conclusion}

Several scholars inquire into the information systems identity and the present paper makes an attempt to identify the intellectual causes that currently hamper those investigations.

Research in information systems is interdisciplinary in nature, however most scholars who look into the cultural core of IS are inclined to maintain an inwardlooking perspective. They tend to overlook what happens in the cognate disciplines such as artificial intelligence, digital humanities and others. So we decided to cross those domains and have found that also cognate disciplines confront foundational issues, which appear symmetrical to those tackled in the information systems. In particular, thinkers argue on broad issues about IT, and debate, for example, how technical progress challenges present and future research.

Authors raise significant arguments but theoretical computer science does not back them. The theories underpinning systems turn out to be fragmentary, uncertain and even contradictory. Those constructions pursue specialist purposes and do not meet the broad themes dealt by philosophers of post-computation disciplines. How can philosophers progress if the basic and comprehensive notions about computing are missing?

The present sad state of TCS can be regarded as a cultural root-cause of the 'identity crisis'; hence the solution to this crisis cannot be obtained inside IS, but outside IS, more precisely should be found in TCS. This field should provide such explanations as to enable philosophers of science to untangle vexed problems.

We have also driven inquiries toward this direction and concluded that the multiple themes of CS are not disjoined but a logical thread connects them [63] [64].

\section{References}

1. Sage S.M. "Information Systems: A Brief Look into History" Datamation, n. 11, 63-69 (1968).

2. Langefors B. "Some Approaches to the Theory of Information Systems," BIT 3, 229-254 (1963).

3. Reisig G.H.R. "Information-system Structure by Communication-Technology Concepts: A Cybernetic Model Approach," Information Processing \& Management, 14(6), pp. 405-417 (1978).

4. Laudon Kenneth C., Laudon J.P. Management information systems: Managing the digital firm, Prentice Hall/CourseSmart (2009).

5. Falkenberg E.D., Hesse W., Lindgree P., Nilsson B.E., Oei J.L.H., Rolland C., Stamper R.K., Assche F.J.M., Verrijn-Stuart A.A., Voss K. (1988). A Framework for Information Systems Concepts, the FRISCO Report (web edition) - Available on March 2017 at: http://www.mathematik.uni-marburg.de/ hesse/papers/fri-full.pdf

6. Lucey T. Management Information System, $9^{\text {th }}$ edition, Thomson Publ. (2005).

7. Wood-Harper A.T., Antill L., Avison D.E. Information Systems Definition: The Multiview Approach. Blackwell Scientific Publications Ltd. (1985). 
8. Grover V., Ayyagari R., Gokhale R., Lim J. "A Citation Analysis of the Evolution and State of Information Systems within a Constellation of Reference Disciplines," Journal of AIS, 7, 270-325 (2006).

9. Baskerville R., Myers D. 2002. "Information Systems as a Reference Discipline," MIS Quarterly (26), pp.1-14 (2002).

10. Markus M.L., Lee A.S. "Special Issue on Intensive Research in Information Systems: Using Qualitative, Interpretive, and Case Methods to Study Information Technology," MIS Quarterly,23(1), 35-38 (1999); MIS Quarterly, 24(1), 1-2 (2000a); MIS Quarterly, 24(3), 473-474 (2000b).

11. Lee A.L. "Retrospect and Prospect: Information Systems Research in the Last and Next 25 Years," Journal of Information Technology 25, 336-348 (2010).

12. Banker R.D., Kauffman R. J. "50th Anniversary Article: The Evolution of Research on Information Systems: A Fiftieth-Year Survey of the Literature in Management Science," Management Science, 50(3), 281-298 (2004).

13. Sidorova A., Evangelopoulos N., Valacich J.S., Ramakrishnan T. "Uncovering the Intellectual Core of the Information Systems Discipline," MIS Quarterly, 32(3), 467-482 (2008).

14. Benbasat I., Zmud R. W. "The identity crisis within the IS discipline: Defining and communicating the discipline's core properties," MIS Quarterly, 27(2), 183-194. (2003).

15. Whitley E.A., Gal U., Kjaergaard A. "Who Do You Think You Are? A Review of the Complex Interplay between Information Systems, Identification and Identity" European Journal of Information Systems, 23(1), 17-35 (2014)

16. Roberts N., Galluch P.S., Dinger M., Grover V. "Absorptive Capacity and Information Systems Research: Review, Synthesis, and Directions for Future Research," MIS Quarterly, 36(2), 625-648 (2012).

17. Alvesson M., Sandberg J. "Habitat and Habitus: Boxed-in versus Box-Breaking Research," Organization Studies, 35 (7), 967-987 (2014).

18. Gibbons M., Limoges C., Nowotny H., Schwartzman S., Scott P., Trow M. The New Production of Knowledge: The Dynamics of Science and Research in Contemporary Society, Sage Publications (1997).

19. Alderman N., Ivory C., Mcloughlin I., Vaughan R. Managing Complex Projects: Networks, Knowledge and Integration, Routledge (2014).

20. Thaller M. "From History to Applied Computer Science in the Humanities." Historical Social Research, Supplement 29 (2017).

21. Robinson L., Priego E., Bawden D. "Library and Information Science and Digital Humanities: Two Disciplines, Joint Future?" In Re-inventing Information Science in the Networked Society, Pehar F., Schlögl C., Wolff C. (eds), Verlag, 44-54 (2015).

22. Hockey S. Electronic Texts in the Humanitie, Oxford University Press (2000).

23. McCarty W. "Humanities Computing: Essential Problems, Experimental Practice" Literary and Linguistic Computing, 17(1), 103-125 (2002).

24. Bod R. A New History of the Humanities: The Search for Principles and Patterns from Antiquity to the Present, Oxford Univ. Press (2013).

25. Salton G. Automatic Text Processing: The Transformation, Analysis, and Retrieval of Information by Computer, Addison-Wesley Longman Publishing Co. (1989)

26. Lancaster F.W., Warner A.J. Information Retrieval Today, Revised edition, Info Resources Publ. (1993).

27. Ellis D. "A Behavioural Approach to Information Retrieval Design," Journal of Documentation, 46(3), 318-338 (1989).

28. Ingwersen P. "Cognitive Perspectives of Information Retrieval Interaction," Journal of Documentation, 52(1), 3-50 (1996). 
29. Lazakidou A.A., Siassiakos K.M. Handbook of Research on Distributed Medical Informatics and E-Health, Medical Information Science Reference Publisher (2008).

30. Kalet I.J. Principles of Biomedical Informatics. Academic Press. (2008).

31. Greenes R.A., Shortliffe E.H. "Medical Informatics: An Emerging Discipline with Academic and Institutional Perspectives," J. of the American Medical Association, 263(8), 1114-1120 (1990).

32. Smith P., Ali S. "Is Software Engineering Really Engineering?" In Brebbia C.A., Ferrante A.J. (eds) Reliability and Robustness of Engineering Software II. Springer, pp 85-95 (1991).

33. Kruchten P. "Putting the Engineering into Software Engineering" Innovations, 4(1), 23-24 (2000).

34. Denning P.J., Freeman P. "Computing's Paradigm" Comm. of the ACM, 52(1), 28-30 (2009).

35. Beizer B. "Software is Different" Annals of Software Engineering, 10(1-4), 293-310 (2000).

36. Herbsleb J.D. "Beyond Computer Science," Proc. of the 27th Intl. Conf. on Software Engineering, 23-27 (2005).

37. Kirsh D. (ed) Foundations of Artificial Intelligence, MIT Press (1992).

38. McCorduck P. Machines who Think: A Personal Inquiry into the History and Prospects of Artificial Intelligence, AK Peters Ltd. (2004).

39. Snodgrass C.R., Szewczak E.J. (eds) Human Factors in Information Systems, IRM Press (2002); Carey J. (ed) Intellect Books (1997), (1995), (1991).

40. Donnellan, B., Larsen, T., Levine, L., DeGross, J. (Eds.) The Transfer and Diffusion of Information Technology for Organizational Resilience, Springer (2006).

41. Lindgaard G. "Some Important Factors for Successful Technology Transfer," In Levin L. (ed) - Diffusion, Transfer and Implementation of Information Technology, Elsevier, 53-66 (1994).

42. Baskerville R., Pries-Heje J. "Diffusing Best Practices: A Design Science Study Using the Theory of Planned Behavior," In Bergvall-Kåreborn B., Nielsen P.A. (eds) Creating Value for All Through IT, Springer, 35-48 (2014).

43. Hsu J., Huang J., Fung V., Robertson N., Jimison H., Frankel R. "Health Information Technology and Physician-Patient Interactions: Impact of Computers on Communication During Outpatient Primary Care Visits," J. American Medical Information Assoc., 12(4), 474-80 (2005).

44. Russel R. J., Norvig P. Artificial Intelligence: A Modern Approach, Prentice Hall (2009).

45. Berry D.M., Fagerjord A. Digital Humanities: Knowledge and Critique in a Digital Age, Wiley and Sons (2017).

46. Gershenfeld N. When Things Start to Think, Hodder \& Stoughton (1999).

47. Peek R.P., Newby G.B. (eds) Scholarly Publishing: The Electronic Frontier, MIT Press (1996).

48. Salles M. Decision-Making and the Information System, John Wiley \& Sons, Inc. (2015).

49. Orlikowski W. J., Iacono C. S. "Research commentary: Desperately seeking the "IT" in IT research - A call to theorizing the IT artifact" Information Systems Research, 12(2), 121-134, (2001).

50. Larsen S.E., Bassnett S., Segal N., Thomsen N.R., Baetens J., Lombardo P., D’haen T. "No Future without Humanities: Literary Perspectives" Humanities, 4, 13-148 (2015).

51. Rech J., Althoff K.D. "Artificial Intelligence and Software Engineering: Status and Future Trends." Künstliche Intelligenz, 18, 5-11 (2004).

52. Charikar M., Chekuri C., Feder T., Motwani R. "Incremental Clustering and Dynamic Information Retrieval” SIAM J. Comput., 33(6), 1417-1440 (2004).

53. Chen H., Chiang R.H.L., Storey V.C. "Business Intelligence and Analytics: From Big Data to Big Impact,” MIS Quarterly, 36(4), 1165-118 (2012). 
54. Mahler T. "Governance Models for Interoperable Electronic Identities" J. of International Commercial Law and Technology, 8(2), 148-159 (2013).

55. Knuth D. The Art of Computer Programming. Vol. 1, second edition, Addison Wesley Longman Publishing Co. (1973).

56. Eden A.H. "Three Paradigms of Computer Science" Minds and Machines, Special issue on the Philosophy of Computer Science, 17(2), 135-167 (2007).

57. Baldwin D. "Is computer science a relevant academic discipline for the 21 st century?" IEEE Computer 44(12), 81-83 (2011).

58. Hayes B. "Cultures of code" American Scientist, 103(1), 10-13 (2015).

59. Tedre M. "Computing as a Science: A Survey of Competing Viewpoints" Minds \& Machines, no. 21, 361-387 (2011).

60. Denning P.J. "Is Computer Science Science ?" Comm. of the ACM, 48(4), 27-31 (2005).

61. Hassan N. R. "Is information systems a discipline? Foucauldian and Toulminian insights" European Journal of Information Systems, 20(4), 456-476 (2011).

62. Rocchi P. "Informatics and Electronics: Some Educational Remarks" Guest editorial, IEEE Trans. on Education, 59(3), 233-239 (2016).

63. Rocchi P. Technology + Culture $=$ Software, IOS Press, Amsterdam (2000).

64. Rocchi P. Logic of Analog and Digital Machines, Nova Science Publishers, N.Y. Revised Edition (2013) 